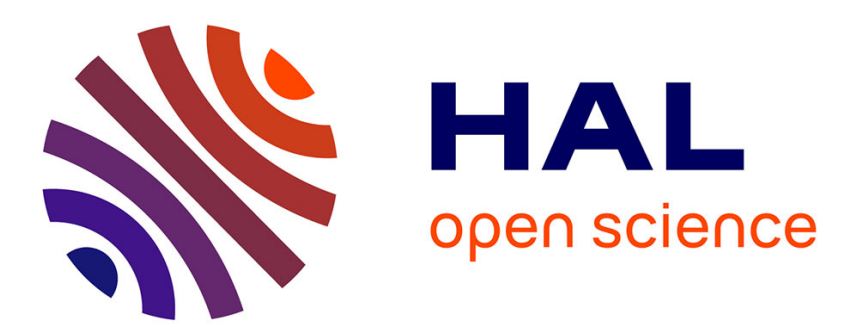

\title{
Self Determination-Based Design To Achieve Acceptance of Assisted Living Technologies For Older Adults
}

\author{
Lucile Dupuy, Charles Consel, Hélène Sauzéon
}

\section{To cite this version:}

Lucile Dupuy, Charles Consel, Hélène Sauzéon. Self Determination-Based Design To Achieve Acceptance of Assisted Living Technologies For Older Adults. Computers in Human Behavior, 2016, 65, 10.1016/j.chb.2016.07.042 . hal-01351332

\section{HAL Id: hal-01351332 \\ https://inria.hal.science/hal-01351332}

Submitted on 3 Aug 2016

HAL is a multi-disciplinary open access archive for the deposit and dissemination of scientific research documents, whether they are published or not. The documents may come from teaching and research institutions in France or abroad, or from public or private research centers.
L'archive ouverte pluridisciplinaire HAL, est destinée au dépôt et à la diffusion de documents scientifiques de niveau recherche, publiés ou non, émanant des établissements d'enseignement et de recherche français ou étrangers, des laboratoires publics ou privés. 


\title{
Self Determination-Based Design To Achieve Acceptance of Assisted Living Technologies For Older Adults
}

\author{
Lucile Dupuy $^{\mathrm{a}, *}$, Charles Consel ${ }^{\mathrm{a}, \mathrm{b}}$, Hélène Sauzéon ${ }^{\mathrm{a}, \mathrm{c}}$ \\ ${ }^{a}$ Inria Bordeaux Sud-Ouest, Talence, France \\ ${ }^{b}$ Bordeaux Institute of Technology, Talence, France \\ ${ }^{c}$ University of Bordeaux, Talence, France
}

\begin{abstract}
Providing technological support to assist older adults in their daily activities is a promising approach to aging in place. However, acceptance is critical when technologies are embedded in the user's life. Recently, Lee et al. established a connection between acceptance and motivation. They approached motivation via the Self-Determination Theory (SDT): the capacity to make choices and to take decisions.

This paper leverages SDT to promote a new design style for gerontechnologies that consists of principles and requirements. We applied our approach to develop an assisted living platform, which was used to conduct a six-month field study with 34 older adults. We show that self-determination is a determining factor of technology acceptance. Furthermore, our platform improved the self-determination of equipped participants, compared to the control group, suggesting that our approach is effective. As such, SDT opens up new opportunities for improving the design process of gerontechnologies.
\end{abstract}

Keywords: Gerontechnologies, User-centered design process, Self-determination 2010 MSC: 00-01, 99-00

\footnotetext{
${ }^{*}$ Corresponding author

URL: phoenix.inria.fr (Hélène Sauzéon)
} 


\section{Introduction}

The demographic context outlined by the World Health Organization (WHO) shows an increase in the population of older people and an increase in life expectancy. Supporting aging in place is a critical challenge for aging population countries, creating a 5 tremendous interest in gerontechnologies. These technologies are dedicated to evaluate, monitor, and/or compensate the difficulties related to aging that may compromise an autonomous and independent living [1]. They form an environmental support, which promotes the adaptation and well-being of older adults in their home [2, 3].

Technology designers and HCI researchers have made considerable efforts to design and develop systems that respond better to the needs and specific characteristics of the older user [4, 5, 6, 7, 8]. For example, the perceptive, motor and cognitive capabilities of the older user have been the subject of significant attention in the design approaches used for gerontechnologies (e.g., [9]). Even though Human Factors and Psychology of Aging have improved the usability of the proposed solutions and contributed to their acceptance by older adults, long term adoption is still a challenge for gerontechnologies [10, 9, 11].

To address this challenge, we propose to leverage user motivation, via the selfdetermination theory (SDT), to achieve technology acceptance. Self-determination is more than an ethical principle; it is grounded in health psychology research and establishes a direct link between self-determination and quality of life/well-being of the older adult [12, 13]. Specifically, the more a person perceives themselves as being self-determined (rather than externally controlled), the more their health and quality of life increase. More specifically, the more an individual's environment supports self-determination, the more this dimension increases, resulting in improved wellbeing [12].

From the perspective of user-centered design [14, 15, 9], self-determination is increasingly used to explain the motivational aspects of users (e.g., attitudinal, emotional) for designing and evaluating technologies. Specifically, the relationship between selfdetermination and technology acceptance and technology uses in young adults has been established.Lee et al. [16] found that when technology supports self-determination, it 
positively impacts technology acceptance. Furthermore, Przybylski et al. explored how digital games fulfill or thwart self-determination needs, and thus promote or discourage sustained engagement and either positive or negative outcomes for players [17]. Recent studies show similar results for acceptance and continuance use intention of e-learning systems for children and young adults [18, 19, 20]. Surprisingly, to the best of our knowledge, there is no study investigating the self-determination model in the context of gerontechnologies.

This paper makes the following contributions.

1. We leverage SDT for assisted living technologies dedicated to older adults. We promote self-determination dimensions as an intrinsic part for the design of gerontechnologies

2. We put SDT dimensions into practice for the development of an assisted living platform for older adults.

3. We conduct a field study to demonstrate that SDT dimensions effectively support self-determination of an individual's environment, improving their selfdetermination performance.

4. We evaluate the impact of self-determination as a determining factor for technology acceptance in older adults.

\section{Related Work}

\section{2.1. Designing gerontechnologies}

Although the user is a central concern in $\mathrm{HCI}$ research, the field of gerontechnologies is still dominated by technology-centered approaches [21, 11, 22]. According to the literature review done by Durick et al. [11], this is due in part to the aging stereotypes of designers and researchers that mistakenly ignore the variabilities

55 in aging. They view an older adult as passively aging, unable to actively manage this process to maintain their daily functioning and well-being. This vision contradicts WHO that promotes, since 2002, active aging, the bio-cultural theory, and the Selection-Optimization-Compensation model of aging proposed by Baltes et al. [23]. 
When these aging stereotypes are carried into the design, they create a mismatch between the technology and the end user [24, 11] with two main concerns:

1. Unmet needs. The technologies developed by designers mainly target the compensation for the loss of an ability due to aging. But in fact, older adults expect technologies to support or optimize the behavioral adaptations they have willingly developed to maintain their daily functioning. This situation makes it difficult for gerontechnologies to attract potential users. Conceptually, technology should be designed by leveraging the spare abilities of older adults, rather than focusing on restoring their declining abilities. Such an approach is promoted by Wobbrock et al. for users with impairments and referred to as ability-based design paradigm [25]. As a result, a technology leveraging and respecting spared adaptative capabilities would be empowering and thus motivating for the older user.

2. Unsatisfactory experience. Often, the purpose and functionalities of gerontechnologies are driven by the needs and requirements of their social and caregiving environments. Even when participatory design has been used, the contributions may not reflect the variabilities of the needs of this population. When older adults acquire gerontechnologies, their functionalities may not match their intrinsic motivations and expected benefits. Their approach and experience with gerontechnologies do not lead them to pursue the use of technologies for their own sake or inherent satisfaction. Consequently, there is a lack of sustained engagement from older users in using gerontechnologies; they end up finding them useless, stigmatizing, and cumbersome. This situation hinders their long term adoption. As a result, a technology with self-decided services would be engaging for the older user.

Recently, Chen and Chan [26] have provided overall evidence of these problems by focusing on the relationship between acceptance and the usage of gerontechnologies in older adults, according to the Technology Acceptance Model (TAM) [27]. Specifically, TAM exhibits two critical attitudinal factors in explaining acceptance and usage of technology: perceived usefulness - "the degree to which a person believes that using 
the particular technology would enhance his/her performance" - and perceived ease of use - "the extent to which a person believes that using a technology is free of effort". Based on a study involving 1012 seniors, Chen and Chan demonstrated that technology acceptance and usage behavior in elderly people are predicted by user characteristics (age, education, gerontechnology related self-efficacy and anxiety, and health deficiencies) and environmental factors (accessibility, assistance and guidance), rather than attitudinal factors (perceived usefulness and ease of use) [26].

In the Human Factors community, it is only recently that a book summarizing a series of recommendations for the design of gerontechnological systems was published [5] (see also [28]). These recommendations give a basis to formulate requirements for designing interfaces (hardware and software) and instructional supports dedicated to the characteristics of the older user, such as vision, hearing, cognition, motor performance and the attitudinal aspects.

The HCI and Human Factors communities have been proposing design techniques to address user characteristics and environmental factors. These techniques include user-centered and participatory design; they actively involve users in the design process for a clear understanding of technology and user requirements. This participatory design takes the form of focus groups, scenario building, idea writing and sketching, and mock-ups [14, 29, 30]. However, a potential limitation reported on these techniques is the lack of generality of the results because they often involve small sets of users, not necessarily representative of the target population [14, 31]. This concern is even more pronounced in the context of older adults, where a wide inter-individual variabilities have been reported [32].

To circumvent these limitations, gerontechnologies need to target a specific segment of older adults to delimit a range of inter-individual variabilities. Participatory design can then sollicit participants that are representative of the target segment. Furthermore, gerontechnologies need to provide a mechanism that allows it to address the spectrum of needs within the target segment. Specifically, just as a clinical intervention needs to be personalized for every individual to be effective [33], a gerontechnology also needs to be customized with respect to each user profile.

The above-mentioned works do not specifically address the intrinsic motivations 
namely, the perceived self-determination elicited by the technology.

\subsection{Designing For The Self-Determination Theory}

The self-determination concept is a modern principle related to the Self-Determination Theory (SDT). Historically, the term self-determination was employed in the context of disability and refers to the "right" to have control in ones own life. A second usage of the term appeared in the literature of motivation, with SDT framework of Deci and Ryan [34, 35]. They define self-determination as the humans internal motivation to engage in activities for which there are no obvious external rewards. As such, an individual is self-motivated in an activity, if it fullfills three needs: (a) the need for recently, studies have demonstrated that technology acceptance as well as technology usage behavior are closely related to the perception of self-determination elicited by the technology. Such findings are highlighted in various domains such as education [18, 19, 20], game playing but also in rehabilitation of cognitively impaired persons serves consideration in understanding of technology acceptance in older adults [41] as well as in cognitively disabled people [42].

Wehmeyer et al. applies SDT to another domain more on education and rehabilitation [43]. In this theoretical framework, self-determination has educational and 

of a persons behavior, (b) an educational and rehabilitation outcome, and (c) in constant evolution through lifelong experiences. According to this model, a behavior is self-determined, if the individuals action reflects four essential characteristics: (1) the individual acts autonomously; (2) the behavior is self-regulated; (3) the person acts in a

[SDT1] - Behavioral autonomy. The person acts according to their own preferences, interests and abilities.

[SDT2] -Self-regulation. The person initiates and reacts to events according to their own ability to act on the environment and to anticipate the results.

[SDT3] - Self-realization. The person knows their strengths and limitations to act in an appropriate way.

[SDT4] - Psychological empowerment. The person is confident in their ability to impact their environment (internalization of the locus of control [45]).

These four dimensions refer to a set of capabilities and a set attitudes, required for an individual to be self-determined. Specifically, self-determination capabilities correspond to SDT1 and SDT2, and self-determination attitudes consist of SDT3 and SDT4 [40]. Scales have been built to assess the four dimensions of self-determination (e.g., LARIDI for adults [46]). We aim to use such scale to determine what is the impact of an SDT-based technology on the self-determination capabilities and attitudes

Interestingly, self-determination means a motivational process where satisfaction comes primarily from the pleasure of setting up an activity rather than its outcome [35]. 
Therefore, a self-determined activity is not necessarily one that is successful or one that is delivered with high performance. Instead, it is a meaningful activity that brings satisfaction to an individual. Consequently, gerontechnologies should first address the activities that are meaningful for an individual and not those that are significant for the social environment [6]. This idea is captured by the first dimension of SDT, namely, behavioral autonomy. This dimension becomes even more meaningful since aging is characterized by continual changes in the interests and preoccupations of the individual (e.g., [47]). Instead of efficiency, comfort and safety, this dimension promotes gerontechnologies as a means to address the meaningful activities for an individual. This is instrumental to guarantee technology acceptance and empowering user experience.

As an example of the SDT dimensions, consider the recurring concern of older adults regarding aging in place. This concern becomes increasingly critical as the person ages (over 80 years old) because of significant functional losses (behavioral autonomy) [47]. Together with this growing concern, the older adult introduces a routinization of their activities to maintain their domestic autonomy (self-regulation) [48]. This routinization is an adaptive response made by the individual on the basis of their awareness of their capabilities (self-realization). Also, a byproduct of this routinization is that the older adult retains control over their environment, and a confidence in being capable of staying in their home (psychological empowerment) [32].

If the designers of gerontechnologies is to adhere to the self-determination approach, these technologies are to be designed in a way that matches the self-adaptive functioning of the declining older adult. In this context, SDT dimensions can be reformulated as objectives realized by the gerontechnologies (see Figure 1). This reformulation is as follows.

1. Support behavioral autonomy. Ensure that the technology addresses an activity meaningful for the person and that the proposed assistance is adequate in that it matches the person's capabilities and expectations.

2. Increase self-regulation opportunities. Enable the person to be in situations where they can take decisions and solve problems by themselves, implementing their own adapted behaviors. 
3. Promote self-realization. Increase the awareness of oneself and of their capabilities to carry out their personal projects.

4. Reinforce psychological empowerment. Reinforce the individual's perception of being in control of their environment and avoid any form of stigmatization about aging in using technology.

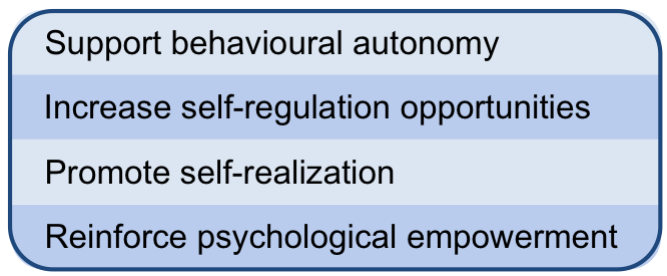

Figure 1: Design objectives related to Self-Determination

\section{Application of SDT Dimensions : The SDT-Assisted Living Technology}

Using our SDT design requirements, we have developed an assisted living platform dedicated to older adults, in collaboration with caregiving organizations. In particular, we targeted users aged 80 years old on average, living alone, and cognitively healthy. Indeed, this target population exhibits age-related decline that threatens their independent living. For example, in France, 15\% of older adults over 85 years live in nursing homes.

We developed assistive applications based on a needs analysis that revealed specific needs in terms of reassurance, concerning the functioning of daily activities at home (preparing a meal, personal care, dressing, etc.) [49]. These applications leverage a range of devices (e.g., motion detectors, contact sensors, smart switches) and software components (e.g., calendar, photo album, address book). Interactions between the user and the assistive applications revolve around a tablet, which is stationary, plugged, and located at a central location in the user's home. These interactions leverage an approach proposed by Consel et al. [50] that allow assistive applications to be scaled up using a unifying notification system [51]. 
[SDT1] - Behavioral Autonomy

to an AppStore) to allow an older adult or their caregiver to install assistive applications (see Figure 2). Each application of the catalog refers to a specific task. An online catalog allows the assistive support to evolve with the user: a new app can be installed (new need) or deleted (need disappears). For example, Mrs X requested help with her meals and personal care, but not for getting up from/going to bed. Consequently, only the "Meals" and "Personal Care" apps were installed. On the other hand, Mrs $\mathrm{Y}$ asked for assistance with her meals and getting from/going to bed. She was thus installed the "Meals" and "Getting from/Going to bed" apps. After a while, Mrs X became more dependant, and needed to be assisted to get dressed, and a nurse came every day to help with personal care. As a result, the "Dressing" app was installed and the "Personal Care" was uninstalled.

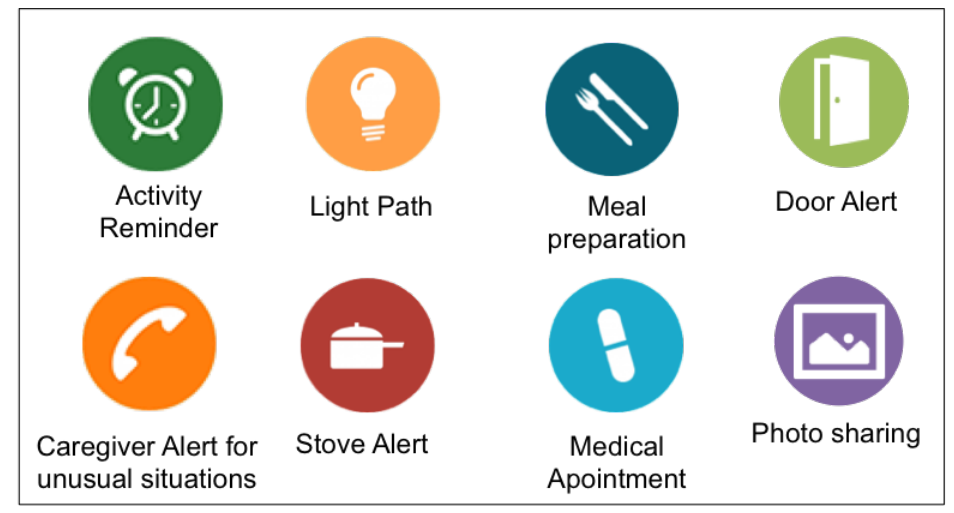

Figure 2: Examples of assistive apps from our catalog

Accessible interface. Regardless of the app installed, interactions are carried out via a touchscreen tablet. Such device is known to be easy to use by the older adult (e.g., [52]). The accessibility of the interface is ensured by the tablet, which acts as a dashboard, receiving and displaying assistance notifications from assistive apps, according to Consel et al.'s approach. Furthermore, interactions are simplified: the user is required a maximum of two screen touches to perform a task from the platform's dashboard (see Figure 
3). The format of the messages is systematically defined according to the standards relative to the perceptive and cognitive capacities of the older adult [53, 54]. However, it can be changed according to the specific capabilities of the person.

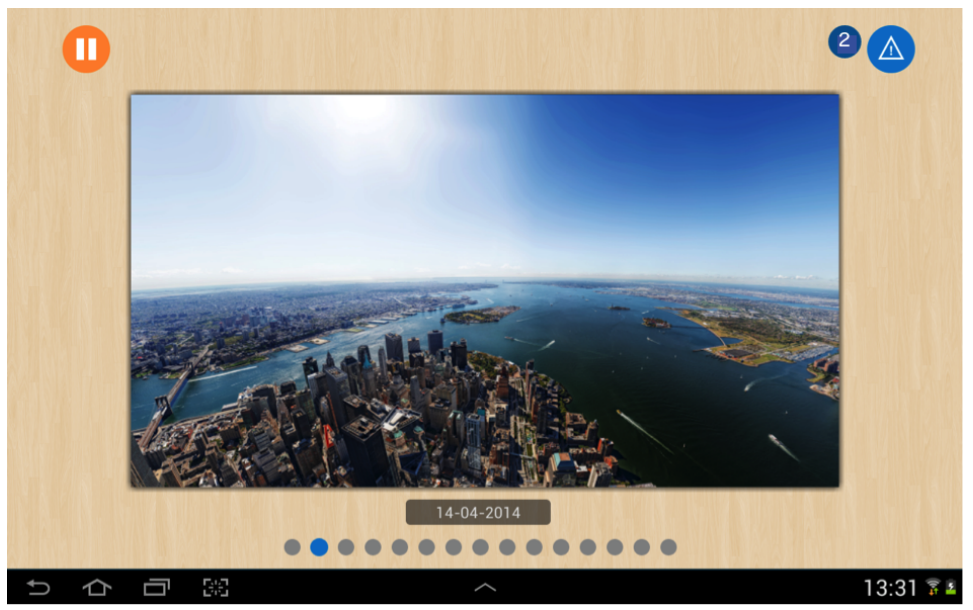

Figure 3: Snapshot of the platform's dashboard

Non-disruptiveness of the physical and social environment. To avoid changing the older adult's home environment, our platform relies on small unobtrusive devices (tablet, motion detectors, contact sensors and electric meters). See Figure 4

a)

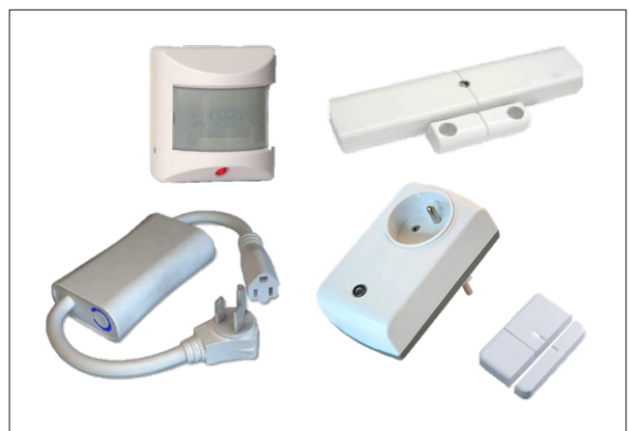

b)

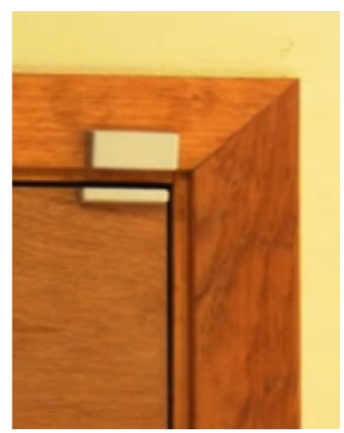

Figure 4: Examples of devices equipping our participants' home

To minimize the changes to the user's physical environment, mock (paper-based) devices are placed in the participant's home for two weeks before the actual devices are 
installed. This approach allows their locations to be adjusted with respect to the user's preferences by an occupational therapist of our study during their visits.

Regarding the social environment, the tablet-based dashboard turns into a digital photo frame when it is idle (no notification), as illustrated in Figure 3 . Photos tions of the assistance system are therefore not automated (as proposed by Stawarz et al. [56] for example) but determined by the person's own activity. By letting the technology be guided by the self-determined activity of the person, it will only react 
according to the person's command. As such, the technology supports the older adult's self-determination.

User-centered interactions. The conditions for delivering assistance notifications on the dashboard are specific to each user. Applications can be configured so that the user can set a time and a delay after which to remind him/her of an activity or a task that should have occurred according to their routine. Specifically, we ask the user how long passed a given time, they should be notified that an activity has not occurred. According to the importance scale of the user, a critical event (absence of activity in the home, opening of a door at night) is signaled on the digital dashboard and/or a caregiver is alerted by SMS or/and by e-mail (Figure 5].

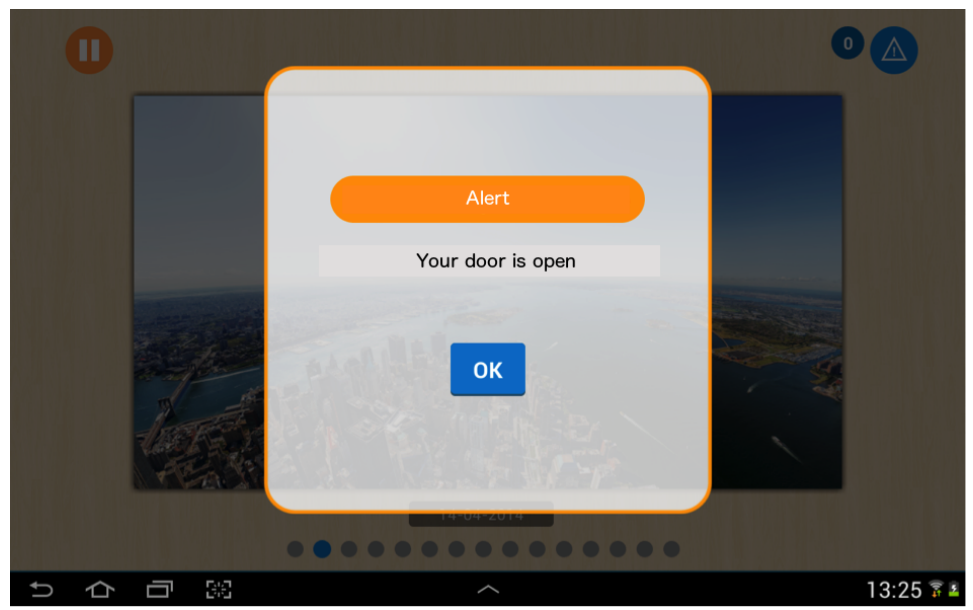

Figure 5: Snapshot for a critical event directly signaled to the user

\section{[SDT3] - Self-Realization}

The system gives feedback to the user on how daily routines have been performed in the form of an overall report: a smiley-face emoticon signals that the routines have been completed ( $>75 \%$ of the planned activities); a neutral emoticon indicates a medium performance (between 50 and $75 \%$ of the planned activities) ; and a sad face emoticon indicates a low performance $(<50 \%$ of the planned activities). Note that this type of activity report is also being promoted for the connected pillbox proposed by 
Lee and Dey [57]. This report keeps the user aware of their abilities to perform their daily routines, and thereby enhance their understanding of their abilities. As such, this feedback improves self-realization. for the user of being able to control the platform and to feel that they manages their assistance.

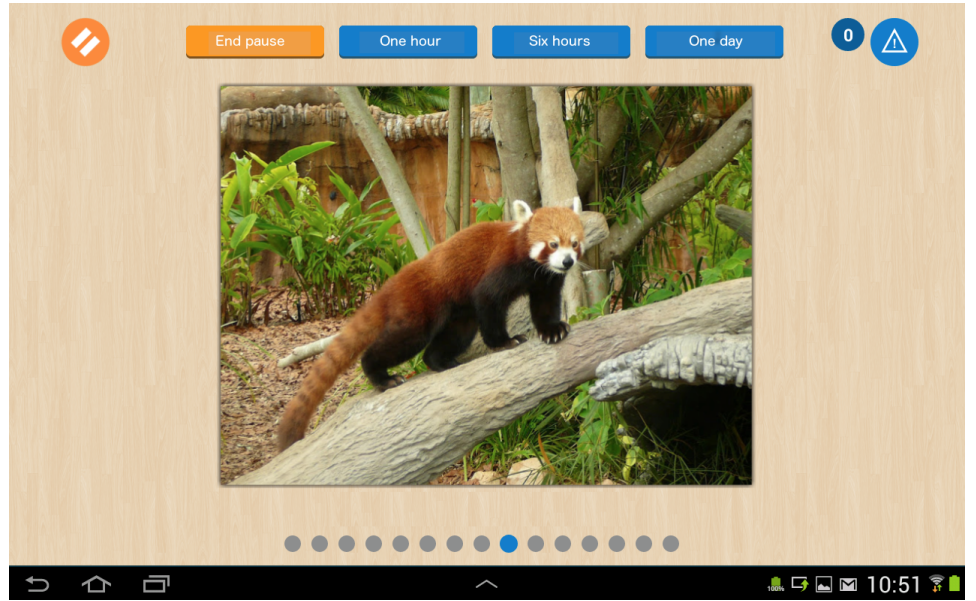

Figure 6: Snapshot showing the possibilities for pausing the assistance

Because older people are more accustomed to paper-based support, we provided them with a concise manual on our platform and assistive apps using this medium (e.g., [59]). This manual reinforces the user's understanding of the technology and thus their control over the system. Additionally, the older user as well as a caregiver, benefit from training sessions on how to use the technology. Finally, there is a 24/7 help desk support. 


\section{DESCRIPTION OF THE FIELD STUDY}

320 based platform on the participants' self-determination and the resulting acceptance and user experience. Our assisted living platform was deployed in the house of 17 community-dwelling older adults (see below) for a 6-month period. We also recruited 17 older adults to form a control group. The first objective of the study was to eval-

\section{EVALUATION OF AN SDT-BASED ASSISTED LIVING PLATFORM WITH A FIELD STUDY}

To study the improvement of self-determination when using our platform, we per-

formed a field deployment in the home of 17 community-dwelling older adults during a six-months study. We first describe our participants, then we detail our measures, and finally we present our experimental results.

\subsection{Participants}

We recruited 34 community-dwelling, old older adults (see Table 11). This was done in collaboration with a public home care service for older adults. We selected 
participants that live alone in their apartment or house, and are cognitively healthy. This choice addressed four concerns. First, this situation simplifies the design space of most assistive applications (e.g., no user-sensitive context). Second, assistive applications can be customized with respect to a unique user, contributing further to user acceptance and satisfaction. Third, as reported in the literature [55], having multiple occupants in a home introduces sources of errors when monitoring activities. In turn, this situation has a negative effects on assistive applications that are context sensitive, such as the activity reminder. A final concern is that older adults living in couple are most of the time assisted by their spouse, and thus are less prompt to request for assistance.

The equipped and control groups of participants were matched according to their age, gender, cognitive status (measured by Mini-Mental State Evaluation (MMSE)) [61], perceived well-being and health (assessed by the physical and mental SF-36) [62]. Furthermore, we assessed subjects' personality with the Locus of Control subscales of the PIC (Personality in Intellectual Aging Context) [63, 64]. These scales estimate the elderly's sense of control in performing everyday activities (e.g., my problem solving ability depends on how healthy I am) with three dimensions: Powerful others, Internal, Chance. Responses are scored on a 6-point Lickert scale ranging from 6 (strongly agree) to 1 (strongly disagree). In an effort to reduce the participants' burden, the PIC was shortened, the resulting instrument reduced each dimension from 12 to 8 items. Thus, each dimension was scored from 8 to 48 , higher scores indicating greater beliefs in internal/chance/other control of one's capabilities. Globally, Table 1 shows that both groups are equivalent in their beliefs.

\subsection{Measures}

Two questionnaires were developed to measure self-determination performance and user acceptance.

\subsubsection{Self-determination}

For self-determination performance, we used the Arc's Self-Determination Scale [65]. This questionnaire was administered to both the control and equipped groups; this was done twice during the study: 1) on the first day of the technology deployment, and 2) 


\begin{tabular}{lccc}
\hline Participants & $\begin{array}{c}\text { Equipped } \\
\text { group } \\
\text { Mean }(S D)\end{array}$ & $\begin{array}{c}\text { Control } \\
\text { group } \\
\text { Mean }(S D)\end{array}$ & $\begin{array}{c}\text { Group } \\
\text { comparison }\end{array}$ \\
\hline Age & $80.00(6.42)$ & $83.18(6.37)$ & $\mathrm{p}>.300$ \\
Gender & 4 males & 5 males & \\
MMSE $_{[0,30]}$ & $27.81(1.51)$ & $27.70(2.20)$ & $\mathrm{p}>.800$ \\
Physical SF-36 $_{[0,100]}$ & $60.07(24.51)$ & $52.30(21.61)$ & $\mathrm{p}>.300$ \\
Mental SF-36 $_{[0,100]}$ & $70.27(19.61)$ & $69.22(19.66)$ & $\mathrm{p}>.800$ \\
PIC Internal $_{[1,48]}$ & $37.76(1.56)$ & $37.59(1.49)$ & $\mathrm{p}>.900$ \\
PIC Chance $_{[1,48]}$ & $29.47(1.26)$ & $31.73(1.49)$ & $\mathrm{p}>.300$ \\
PIC Powerful Others $_{[1,48]}$ & $15.71(1.81)$ & $16.56(1.69)$ & $\mathrm{p}>.700$ \\
\hline SD=Standard Deviation & & &
\end{tabular}

Table 1: Participant profiles

after 6 months of using the platform (these two stages are noted $T_{0}$ and $T_{6}$, respectively).

The Arc's Self-Determination Scale 72-item scale is composed by four dimensions: section I measures autonomy (32 items), section II measures self-regulation ( 9 items). The third section assesses psychological empowerment (15 items) and the last section measures self-realization, including self-awareness and self-knowledge (14 items). However, several items of this scale were excluded because of their inappropriateness with respect to the topic of our study (in particular, items related to working conditions). The 55-selected items can be found in Section Appendix A.

Our final scale was composed by 55 items, including 26 items for measuring autonomy, 4 items for self-regulation, 10 items for empowerment and 15 items for selfrealization. The items are scored the same way as the original Arc's scale, where a higher score indicates a better self-determination performance. All raw scores were mapped into percentages. 


\subsubsection{User Acceptance}

The user acceptance questionnaire was only administered to the equipped group, after six onth of platform usage. This questionnaire is inspired by an existing online tool proposed by Hassenzahl [66] $]^{1}$ This measurement tool decomposes acceptance into five dimensions: ergonomic quality, hedonic quality, appealingness, anxiety and safety perception, and social influence. Answers to the questionnaire range over a scale of 7 points, from -3 to 3, including two antonyms (e.g., nervous/relaxed). Each acceptance dimension of the questionnaire consists of 6 items. The global score (from - 3 to 3 ) is computed by averaging the scores of the answers collected for the questionnaire. High acceptance is denoted by a high score.

Importantly, we did not use the Technology Acceptance Model (TAM) that stresses the perceived usefulness and perceived ease of use as the main attitudinal factors towards technology acceptance [27, 67]. Indeed, recall that Chen and Chan demonstrated that technology acceptance is predicted by user characteristics, rather than attitudinal factors [26]. As a result, we decided to measure user acceptance beyond the two main attitudinal factors of TAM, including dimensions related to user experience using Hassenzahl's tool [66].

\subsection{Statistical Analysis}

Several statistical analyses were performed according to the study objectives.

1. To evaluate whether our SDT-based platform changes the self-determination performance of our equipped participants. On the four self-determination scores (autonomy, self-regulation, empowerment and self-realization), we performed mixed MANOVAs with the following design: time as a within-subject independent factor with two levels $\left(T_{0} v s . T_{6}\right)$, group as a between-subject independent factor with two levels (equipped v.s. control). A significant change over time in self-determination performance for the equipped group will be obtain if the two-way interaction effect (time*group) reaches the significance. In this case, mixed ANOVA with the same factor design was performed on each of the SD

\footnotetext{
${ }^{1}$ http://attrakdiff.de
} 
dimensions as a dependent measure. In other words, all these analyses aimed to exhibit the significance of the change of self-determination performance over time.

2. To assess the acceptance our SDT-based platform, the five dimensions of the Hassenzahl tool were submitted to a MANOVA analysis with the time factor as a within-subject independent factor. This analysis is followed by a $t_{\text {Student }}$ comparison for each dimension.

3. To examine whether the initial self-determination performance of our equipped participants is related to their acceptance and user experience of our platform. We performed a Bravais-Pearson correlation analysis between self-determination measures and acceptance measures.

Moreover, effect size $\left(\eta^{2}\right)$ was measured for every analysis. All the statistical analysis were performed using SAS SPSS Statistics 20.

\subsection{Results}

Evolution of self-determination for equipped and non-equipped older users. Our results are summarized in Figure 7 Overall, our MANOVA analysis revealed that a positive change in self-determination performance of our equipped participants are significant over time, for the four dimensions (two-way interaction effect, $\mathrm{F}(4,29)=2.72, \mathrm{p}=<.05$, $\eta^{2}=.272$ ). No significant change was measured for the non-equipped participants.

Let us now examine each self-determination dimension. For autonomy, an interaction effect between time and group factor $(\mathrm{F}(1,32)=1.87 ; \mathrm{p}>.100)$ did not reach significance. Nevertheless, the examination of the means indicates that the equipped participants gained perceived autonomy over the six-month study, while perceived autonomy decreases for the control group. In contrast, for the self-regulation score, the two-way interaction effect was significant $\left(\mathrm{F}(1,32)=3.94 ; \mathrm{p}=.05 ; \eta^{2}=.055\right)$. The examination of the means indicates that the equipped participants gained perceived self-regulation over the six-month study, while perceived self-regulation remains unchanged for the control group. The same observation applies for the self-realization 
performance $\left(\mathrm{F}(1,32)=17.40 ; \mathrm{p}<.01 ; \eta^{2}=.222\right)$. Additionally, the two-way interaction effect is nearly obtained for the empowerment performance $(F(1,32)=3.60$; $\left.\mathrm{p}=.06 ; \eta^{2}=.101\right)$. The examination of the means reveals that the equipped participants gained perceived psychological empowerment over the six-month study, while perceived psychological empowerment decreases with time for the control group. A detailed description of the MANOVA and the ANOVAs are given in Section Appendix A

According to these results, we can see that the use of our platform has an impact on user's perceptions of self-determination; this validates the design of our technology. However, even if self-determination is enhanced by this platform, it is important that the gerontechnology be accepted by the users. For this purpose, we studied the relationships between self-determination and technology acceptance within our equipped group.

Evolution of acceptance for equipped participants. Overall, acceptance scores at the beginning of the experiment, as well as at 6 months, are high and positive: they are all over 1 point. Acceptance scores at 6 months of use are presented in Figure 8 The MANOVA analysis revealed a significant effect of time $\left(\mathrm{F}(5,12)=3.57 ; \mathrm{p}<.05 ; \eta^{2}=\right.$ .598). The univariate ANOVA with time factor on each acceptance measure indicates the following results: the ergonomic value increases with time $(F(1,16)=4.69 ; \mathrm{p}<$ $\left..05 ; \eta^{2}=.227\right)$; the hedonic value increases with time $\left(\mathrm{F}(1,16)=6.05 ; \mathrm{p}<.03 ; \eta^{2}=\right.$ $.275)$.

Relationships between self-determination and technology acceptance. To highlight the relationships between self-determination and technology acceptance, we performed Bravais-Pearson inter-correlation between self-determination benefits and global acceptance benefits, across time. The self-determination benefits were determined as follows. We first summed the scores for all SD dimensions, for each time condition (total of SD at $T_{0}$ and total of SD at $T_{6}$ ); we then substracted $T_{6}$ from $T_{0}$; finally, we compute a ratio by dividing the result of the substraction by the sum of total SD dimensions at $T_{0}$ and $T_{6}$. These calculations amount to the following formulae 
$475 \frac{\operatorname{Total}\left(S D\left(T_{6}\right)\right)-\operatorname{Total}\left(S D\left(T_{0}\right)\right)}{\operatorname{Total}\left(S D\left(T_{0}\right)\right)+\operatorname{Total}\left(S D\left(T_{6}\right)\right)}$. The resulting value allows us to assess how much proportional gain is measured for all SD dimensions. The same approach is applied to the acceptance score $\frac{\operatorname{Total}\left(\operatorname{Accept}\left(T_{6}\right)\right)-\operatorname{Total}\left(\operatorname{Accept}\left(T_{0}\right)\right)}{\operatorname{Total}\left(\operatorname{Accept}\left(T_{0}\right)\right)+\operatorname{Total}\left(\operatorname{Accept}\left(T_{6}\right)\right)}$. The correlation analysis indicated a high positive relationship between self-determination benefits and acceptance benefits $(\mathrm{R}=.50 ; \mathrm{p}=.04)$; the higher self-determination benefits get the better for technology acceptance.
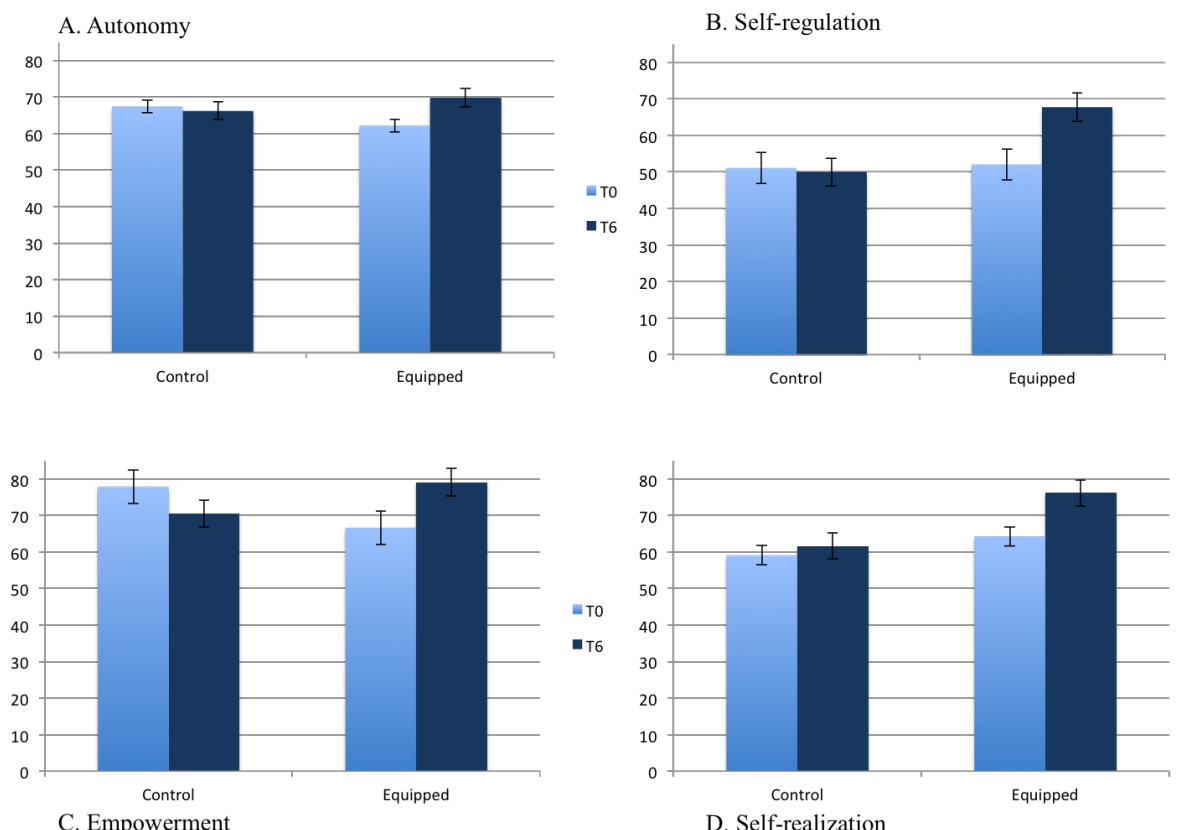

C. Empowerment

D. Self-realization

Figure 7: Evolution of self-determination dimensions (A. Autonomy; B. Self-regulation; C. Empowerment; D. Self-realization) for equipped and control groups from $T_{0}$ (in pale blue) to $T_{6}$ (in dark blue)

\section{Discussion}

The goal of this paper was to promote SDT into the design of gerontechnologies. While classical Human Factors approaches revolve around age-related user changes (physical and cognitive functioning), SDT focuses on motivational factors to drive the design technologies. As such, SDT works in synergy with classical Human Factors approaches for promoting the human-centered approach into the design process. 


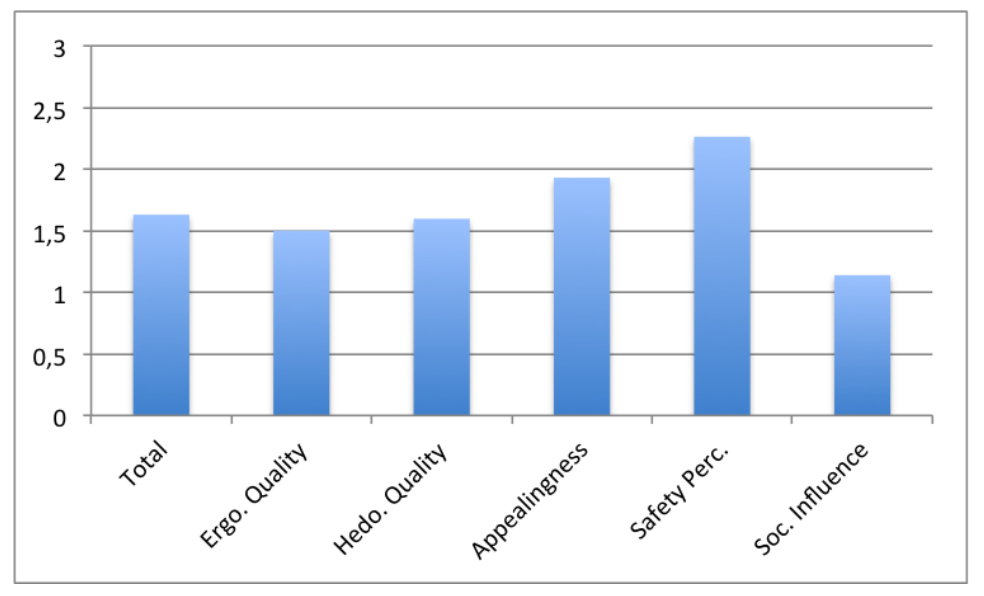

Figure 8: Acceptance scores at 6 months of use. The global score is presented on the left, followed by the scores for each dimensions (i.e., ergonomic quality, hedonic quality, appealingness, safety perception and social influence).

In this work, we have explored the concept of self-determination towards improving the design process of gerontechnologies by proposing specific principles and requirements. We put this approach to practice by developing an assisted living platform. We conducted a six-month field study with 23 older adults to assess the platform impact on their self-determination and the resulting acceptance. A major result of this study is that a 6-month use of our SD-based platform improves user's self-determination performance in every dimensions: autonomy, self-regulation, empowerment and selfrealization. In constrast, no change or even deterioration was observed among nonequipped participants. Indeed, psychological empowerment performance has diminished in the non-equipped group. This observation is consistent with aging studies revealing that the loss of sense of control on the environment is sensible with increasing age [68.

These results validate our approach to promote SDT requirements to design gerontechnologies. We demonstrate the effectiveness of our SDT design principles by showing their impact on the self-determination state of the equipped participants. A second important result is the strong relationship revealed between self-determination dimensions and technology acceptance dimensions.This relationship mirrors the findings re- 
ported by Lee, Lee \& Hwang [16] for young users. Interestingly, their work exhibits

positive relations, whereas our work shows negative relations. More specifically, a negative influence of the self-determination performance on technology acceptance is reported. The same negative influence has also been reported in past studies for the health condition on Internet usage [69] and assistive technology adoption [70]. The finding that people with poor self-determination conditions are more likely to use technology might be an indication that older people intend to use gerontechnology as a compensation, whereby the use of technology can increase autonomy and, to some extent, compensate for age-related self-determination deficiencies [71]. These remarks are consistent with Chen and Chan who state that user characteristics in older adults determine user acceptance, rather than attitudinal factors [26].

Even if the sample size of our field study is a statistical limitation, to the best of our knowledge, there is no study aiming at using SDT as design requirements for assistive technologies. Furthermore, there is no study measuring the effect of SDT-based technologies on the self-determination performance of users. Finally, there is no research reporting a relationship between self-determination performance and technology acceptance in older adults.

\section{SDT-Based Design Requirements [DR]}

We now reflect on this design process and outline four classes of requirements, following the four SDT dimensions, that could be used to design gerontechnologies.

\section{[DR1] - Supporting behavioral autonomy}

- Variability and evolution of tasks of interest. The scope of activities addressed by the technology should be wide and extensible to cover the activities of interest of the older adult and their evolution over time.

- Accessible interface. The assistance proposed by the technology should be accessible to the person and should help them carry out the target activity. Specifically, it should match the perceptive, motor and cognitive capabilities of the older adult using the assistance, leveraging existing Human Factors methods. 
- Non-disruptiveness of the physical and social environment. The technological assistance must be unobtrusively integrated into the physical and social environment of the older adult. Indeed, this is where the user has developed their habits and has adapted to be behaviorally autonomous.

[DR2] - Increasing self-regulation opportunities

- Reinforcement of adaptative behaviors. The assistive support must be complementary to the older adult's: it should leverage adaptive behaviors and skills of the user, instead of taking over from the user. Substituting the user by an automated system, as is promoted by home automation, is to be avoided, except when the user explicitly requests such support for their own comfort.

- Improvement of decision making. The level and the form of the assistance given by the system are defined and decided by the user to meet their abilities of selfregulation.

- User-centered interactions. The older user always remains the causal agent of interactions with the system whether these be passive or active (expected input from the user). During interactions between the older user and the system, the system should always provide the user with the necessary latitude to respond to their self-regulation expectations.

\section{[DR3] - Promoting self-realization}

The system should give feedback as it assists the older user in performing a desired activity. This report should enable the user to maintain their self-awareness and their capabilities to perform the meaningful tasks. To achieve this goal, the system should maintain context-awareness information about an ongoing activity.

[DR4] - Reinforcing psychological empowerment

The system must allow the older adult to change as many functionalities as possible, increasing their perception of control over their environment. 


\section{Conclusions}

SDT-based technologies allow the user to be the causal agent of the technology's

560 autonomously and perform meaningful activities. SDT puts the users' motivation at the core of the assistance system, ensuring the meaning of the technology for the person. We promote these requirements as a way to provide a more successful and durable match between the older user's expectations and the design of the technology. In fact,

[2] D. G. Morrow, W. A. Rogers, Environmental support: An integrative framework, Human Factors: The Journal of the Human Factors and Ergonomics Society 50 (4) (2008) 589-613.

[3] M. Mokhtari, H. Aloulou, T. Tiberghien, J. Biswas, D. Racoceanu, P. Yap, New 
trends to support independence in persons with mild dementia-a mini-review, Gerontology 58 (6) (2012) 554-563.

[4] A. D. Fisk, W. A. Rogers, N. Charness, S. J. Czaja, J. Sharit, Designing for older adults: Principles and creative human factors approaches, CRC press, 2012.

[5] N. Charness, G. Demiris, E. Krupinski, Designing telehealth for an aging population: A human factors perspective, CRC Press, 2011.

[6] S. E. Lindley, R. Harper, A. Sellen, Designing for Elders : Exploring the Complexity of Relationships in Later Life, in: BCS-HCI '08 Proceedings of the 22nd British HCI Group Annual Conference on People and Computers: Culture, Creativity, Interaction, 2008, pp. 77-86.

[7] M. R. Mcgee-lennon, M. K. Wolters, S. Brewster, User-Centred Multimodal Reminders for Assistive Living, in: CHI 2011, Vancouver, Canada, 2011, pp. 21052114.

[8] I. Arreola, Z. Morris, M. Francisco, K. Connelly, K. Caine, G. White, M. Hall, From Checking On to Checking In : Designing for Low Socio-Economic Status Older Adults, in: Proceedings of the 32nd annual ACM conference on Human factors in computing systems, Toronto, 2014, pp. 1933-1936.

[9] W. A. Rogers, A. D. Fisk, Toward a psychological science of advanced technology design for older adults, The Journals of Gerontology Series B: Psychological Sciences and Social Sciences (2010) gbq065.

[10] E. Hernández-Encuentra, M. Pousada, B. Gómez-Zúñiga, ICT and Older People: Beyond Usability, Educational Gerontology 35 (3) (2009) 226-245. doi:10.1080/03601270802466934.

URL

http://www.tandfonline.com/doi/abs/10.1080/ 03601270802466934

[11] J. Durick, M. Brereton, F. Vetere, B. Nansen, Dispelling Ageing Myths in Technology Design, in: OzCHI'13, Adelaide, Australia, 2013, pp. 467-476. 
[12] B. P. O'Connor, R. J. Vallerand, Motivation, self-determination, and person environment fit as predictors of psychological adjustment among nursing home residents., Psychology and Aging 9 (2) (1994) 189.

[19] K.-C. Chen, S.-J. Jang, Motivation in online learning: Testing a model of selfdetermination theory, Computers in Human Behavior 26 (4) (2010) 741-752.

[20] J. C. Roca, M. Gagné, Understanding e-learning continuance intention in the workplace: A self-determination theory perspective, Computers in Human Be-

[21] J. Preece, H. Sharp, Y. Rogers, Interaction Design-beyond human-computer interaction, John Wiley \& Sons, 2015. 
[22] J. Vines, G. Pritchard, P. Wright, P. Olivier, K. Brittain, An age-old problem: Examining the discourses of ageing in hci and strategies for future research, ACM Transactions on Computer-Human Interaction (TOCHI) 22 (1) (2015) 2.

[23] P. B. Baltes, M. Baltes, A. Freund, F. Lang, The measurement of selection, optimization, and compensation (SOC) by self report: Technical report 1999, MaxPlanck-Institut für Bildungsforschung, 1999.

[24] P. Sengers, B. Gaver, Staying open to interpretation: engaging multiple meanings in design and evaluation, in: Proceedings of the 6th conference on Designing Interactive systems, ACM, 2006, pp. 99-108.

[25] J. O. Wobbrock, S. K. Kane, K. Z. Gajos, S. Harada, J. Froehlich, Ability-based design: Concept, principles and examples, ACM Transactions on Accessible Computing (TACCESS) 3 (3) (2011) 9.

[26] K. Chen, A. H. S. Chan, Gerontechnology acceptance by elderly hong kong chinese: a senior technology acceptance model (stam), Ergonomics 57 (5) (2014) $635-652$.

[27] F. D. Davis, Perceived usefulness, perceived ease of use, and user acceptance of information technology, MIS quarterly (1989) 319-340.

[28] M. J. Scherer, Assistive technologies and other supports for people with brain impairment, Springer Publishing Company, 2012.

[29] O. Demirbilek, H. Demirkan, Universal product design involving elderly users: a participatory design model, Applied ergonomics 35 (4) (2004) 361-370.

[30] K. Vredenburg, J.-Y. Mao, P. W. Smith, T. Carey, A survey of user-centered design practice, in: Proceedings of the SIGCHI conference on Human factors in computing systems, ACM, 2002, pp. 471-478.

[31] W. E. Mackay, The interactive thread: exploring methods for multi-disciplinary design, in: Proceedings of the 5th conference on Designing interactive systems: processes, practices, methods, and techniques, ACM, 2004, pp. 103-112. 
[32] U. Lindenberger, M. Lövdén, M. Schellenbach, S.-C. Li, A. Krüger, Psychological principles of successful aging technologies: A mini-review, Gerontology 54 (1) (2008) 59-68.

[33] H. Amieva, P. H. Robert, A.-S. Grandoulier, C. Meillon, J. De Rotrou, S. Andrieu, C. Berr, B. Desgranges, B. Dubois, C. Girtanner, et al., Group and individual cognitive therapies in alzheimer's disease: the etna3 randomized trial, International Psychogeriatrics (2015) 1-11.

[34] E. L. Deci, R. M. Ryan, The general causality orientations scale: Selfdetermination in personality, Journal of research in personality 19 (2) (1985) $109-134$

[37] K. M. Sheldon, C. P. Niemiec, It's not just the amount that counts: balanced need satisfaction also affects well-being., Journal of personality and social psychology 91 (2) (2006) 331.

[38] R. Ryan, Self determination theory and well being, Social Psychology 84 (2009)

[39] M. Caouette, R. Plichon, D. Lussier-Desrochers, Autodétermination et création du "chez-soi": un nouvel enjeu pour les technologies de soutien aux personnes en situation de handicap, Terminal. Technologie de l'information, culture \& société (116).

[40] M. L. Wehmeyer, Self-determination and individuals with severe disabilities: Reexamining meanings and misinterpretations, Research and Practice for Persons with Severe Disabilities 30 (3) (2005) 113-120. 
[41] C. Oppenauer, Motivation and needs for technology use in old age, Gerontechnology 8 (2) (2009) 82-87.

[42] S. E. Stock, D. K. Davies, M. L. Wehmeyer, Y. Lachapelle, Emerging new practices in technology to support independent community access for people with intellectual and cognitive disabilities, NeuroRehabilitation 28 (3) (2011) 261-269.

[43] M. L. Wehmeyer, The arc's self-determination scale: Procedural guidelines.

[44] U. W. Hellström, A. Sarvimäki, Experiences of self-determination by older persons living in sheltered housing, Nursing ethics 14 (3) (2007) 413-424.

[45] B. Weiner, H. Heckhausen, W.-U. Meyer, Causal ascriptions and achievement behavior: a conceptual analysis of effort and reanalysis of locus of control., Journal of personality and social psychology 21 (2) (1972) 239.

[46] M. Wehmeyer, Y. Lachapelle, D. Boisvert, D. Leclerc, R. Morrissette, Léchelle dautodétermination version pour adultes, Laboratoire de Recherche Interdépartemental en Déficience Intellectuelle (LARIDI), Université du Québec à Trois-Rivières. Trois-Rivières.

[47] T. L. Mitzner, S. E. McBride, L. H. Barg-Walkow, W. A. Rogers, Selfmanagement of wellness and illness in an aging population, Reviews of Human Factors and Ergonomics 8 (1) (2013) 277-333.

[48] J. Bouisson, Routinization preferences, anxiety, and depression in an elderly french sample, Journal of Aging Studies 16 (3) (2002) 295-302.

[49] L. Aguilova, H. Sauzéon, É. Balland, C. Consel, B. N'Kaoua, AGGIR scale: a contribution to specifying the needs of disabled elders, Revue Neurologique 170 (3) (2014) 216-221.

[50] C. Consel, L. Dupuy, H. Sauzéon, A unifying notification system to scale up assistive services, in: Proceedings of the 17th international ACM SIGACCESS conference on Computers \& accessibility, ACM, 2015, to appear. 
[51] L. Caroux, C. Consel, L. Dupuy, H. Sauzéon, Verification of daily activities of older adults: a simple, non-intrusive, low-cost approach, in: Proceedings of the 16th international ACM SIGACCESS conference on Computers \& accessibility, ACM, 2014, pp. 43-50.

[52] L. Findlater, J. E. Froehlich, K. Fattal, J. O. Wobbrock, T. Dastyar, Age-related differences in performance with touchscreens compared to traditional mouse input, in: Proceedings of the SIGCHI Conference on Human Factors in Computing Systems, ACM, 2013, pp. 343-346.

[53] International Standard ISO 9999: 2007 (E) Assistive products for persons with disability-Classification and terminology 4th ed (2007).

[54] T. ISO, 22411, Ergonomics data and guidelines for the application of ISO/IEC Guide 71.

[55] B. Logan, J. Healey, M. Philipose, E. M. Tapia, S. Intille, A Long-Term Evaluation of Sensing Modalities for Activity Recognition, in: Springer-Verlag (Ed.), Ubicomp, Berlin Heidelberg, 2007.

[56] K. Stawarz, A. L. Cox, A. Blandford, Don't forget your pill!: designing effective medication reminder apps that support users' daily routines, in: Proceedings of the 32nd annual ACM conference on Human factors in computing systems, ACM, 2014, pp. 2269-2278.

[57] M. L. Lee, A. K. Dey, Real-time feedback for improving medication taking, in: Proceedings of the 32nd annual ACM conference on Human factors in computing systems, ACM, 2014, pp. 2259-2268.

[58] K. E. Caine, C. Y. Zimmerman, Z. Schall-Zimmerman, W. R. Hazlewood, A. C. Sulgrove, L. J. Camp, K. H. Connelly, L. L. Huber, K. Shankar, Digiswitch: design and evaluation of a device for older adults to preserve privacy while monitoring health at home, in: Proceedings of the 1st ACM International Health Informatics Symposium, ACM, 2010, pp. 153-162. 
[59] S. J. Czaja, J. Sharit, Designing training and instructional programs for older adults, CRC Press, 2012.

[60] J. L. Wetherell, C. A. Reynolds, M. Gatz, N. L. Pedersen, Anxiety, cognitive performance, and cognitive decline in normal aging, The Journals of Gerontology Series B: Psychological Sciences and Social Sciences 57 (3) (2002) P246-P255.

[61] M. F. Folstein, S. E. Folstein, P. R. McHugh, Mini-mental state: a practical method for grading the cognitive state of patients for the clinician, Journal of psychiatric research 12 (3) (1975) 189-198.

[62] J. E. Ware Jr, C. D. Sherbourne, The mos 36-item short-form health survey (sf36): I. conceptual framework and item selection, Medical care (1992) 473-483.

[63] M. E. Lachman, Locus of control in aging research: a case for multidimensional and domain-specific assessment., Psychology and aging 1 (1) (1986) 34.

[64] H. Levenson, Differentiating among internality, powerful others, and chance.

[65] N. Wehmeyer, Michael L; Bolding, Self-determination accross living and working environments: a matched-samples study of adults with mental retardation, Mental Retardation 37 (1999) 353-63.

[66] M. Hassenzahl, The interplay of beauty, goodness, and usability in interactive products, Human-Computer Interaction 19 (4) (2004) 319-349.

[67] V. Venkatesh, M. G. Morris, G. B. Davis, F. D. Davis, User acceptance of information technology: Toward a unified view, MIS quarterly (2003) 425-478.

[68] M. E. Lachman, Perceived control over aging-related declines adaptive beliefs and behaviors, Current Directions in Psychological Science 15 (6) (2006) 282286.

[69] L. U. Nayak, L. Priest, A. P. White, An application of the technology acceptance model to the level of internet usage by older adults, Universal Access in the Information Society 9 (4) (2010) 367-374. 
[70] E. M. Agree, V. A. Freedman, J. C. Cornman, D. A. Wolf, J. E. Marcotte, Reconsidering substitution in long-term care: when does assistive technology take the place of personal care?, The Journals of Gerontology Series B: Psychological 775 Sciences and Social Sciences 60 (5) (2005) S272-S280.

[71] F. Kohlbacher, C. Herstatt, T. Schweisfurth, Product development for the silver market, in: The Silver Market Phenomenon, Springer, 2011, pp. 3-13. 


\section{Appendix A. The Arc's Self-Determination Scale}

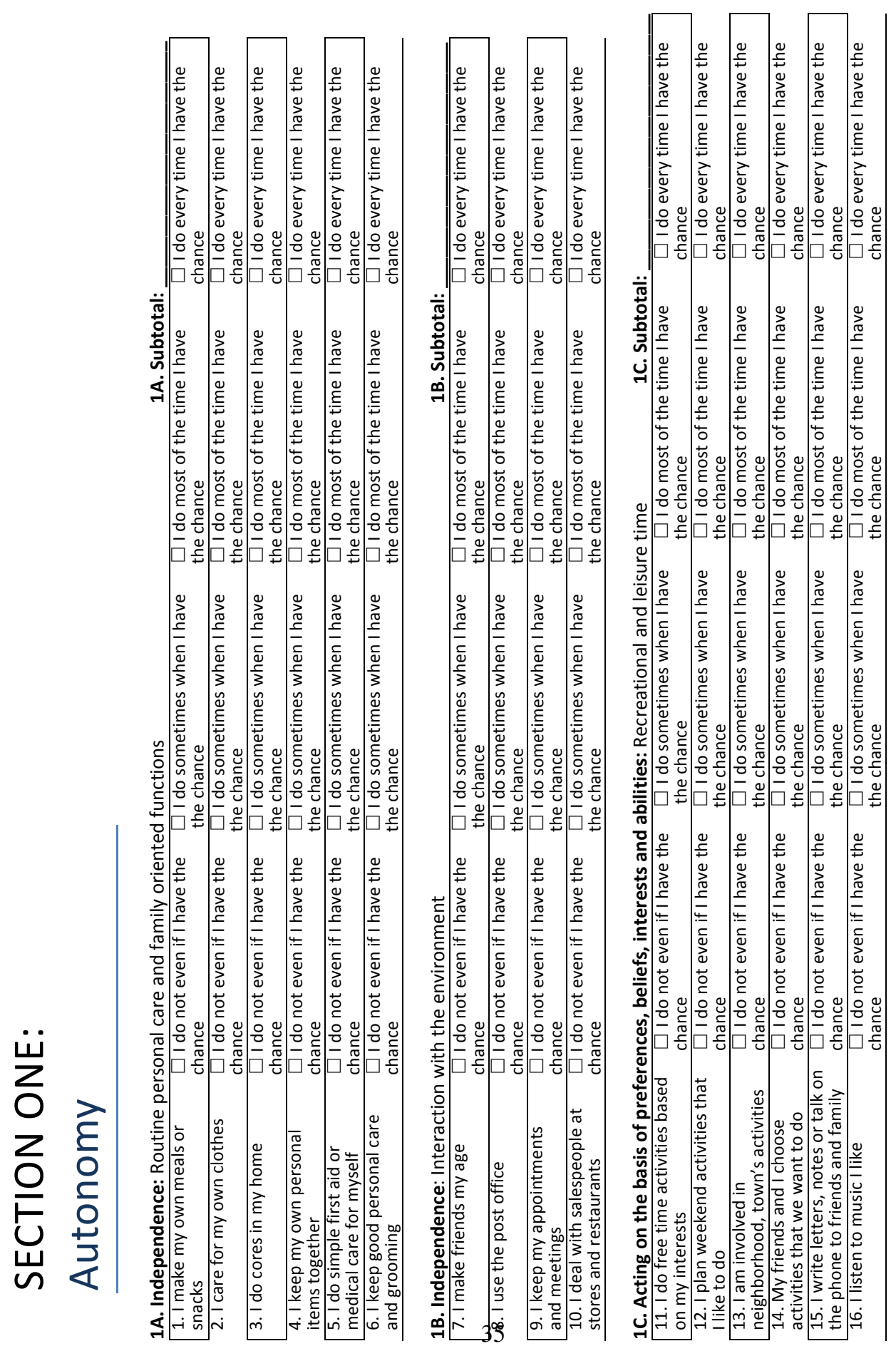




\section{SECTION TWO:}

\section{Self-Regulation}

\section{A. Interpersonal cognitive problem-solving}

33. Beginning: You are sitting in a planning meeting with your employer. You want to take a class where you can learn how to use a computer, whereas your employer wans
or the other. Middle:

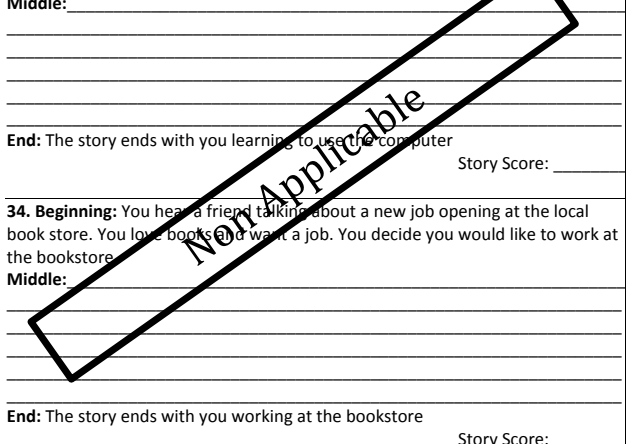

35. Beginning: Your friends are acting like they are mad at you. You are upset out this. Middle:

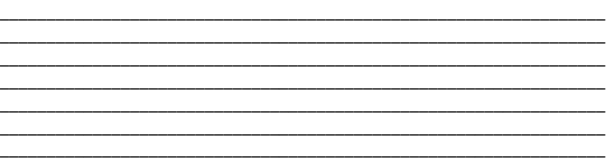

End: The story ends with you and your friends getting along just fine.

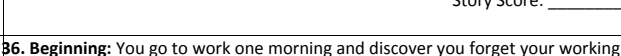

36. Beginning: You go to work one morning and discover you forget your workin femplate that you need. You are upset because you that template to do your work.
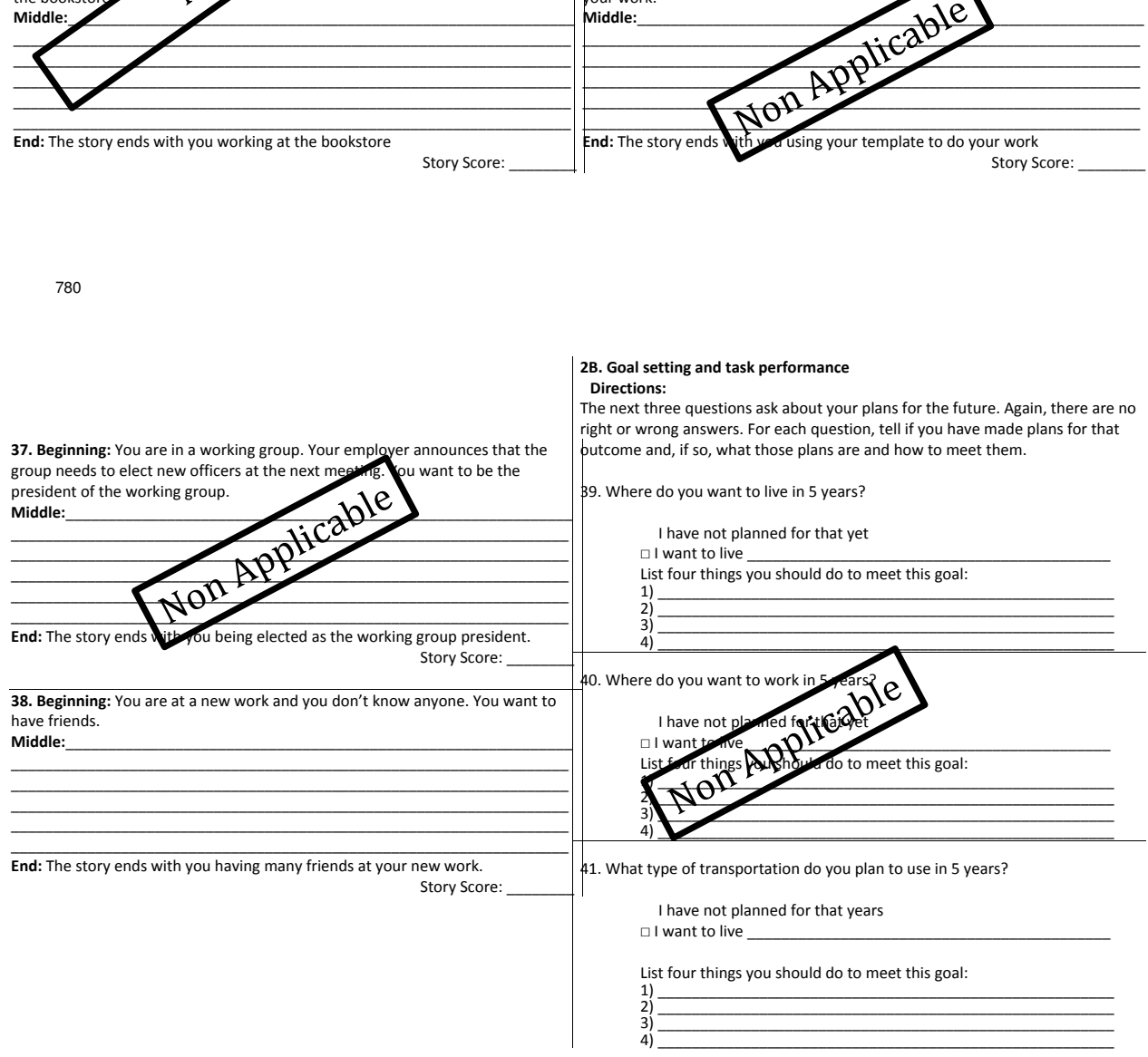


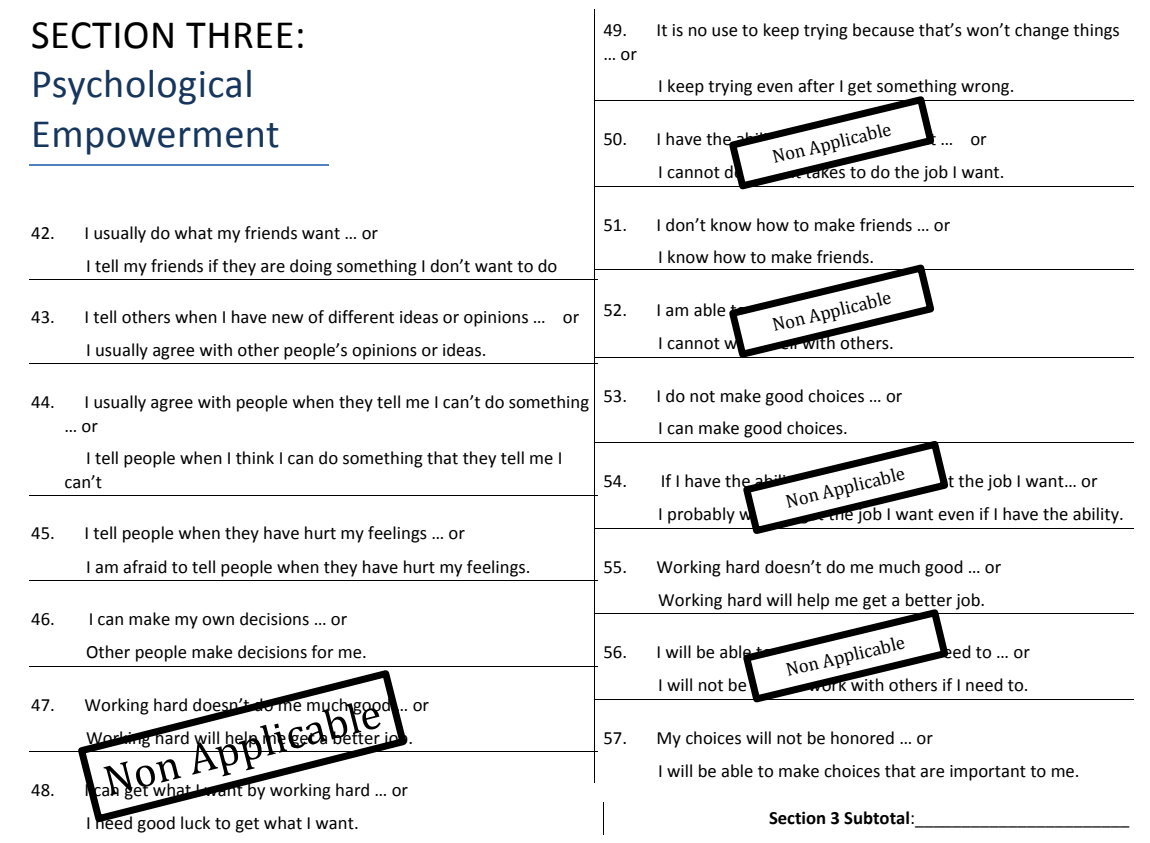

\section{SECTION FOUR:}

\section{Self-Realization}

\begin{tabular}{|c|c|c|c|c|c|}
\hline \multirow{2}{*}{$\begin{array}{l}\text { 58. I do not fell ashamed of any } \\
\text { of my emotions. }\end{array}$} & \multirow[b]{2}{*}{ Agree } & \multirow[b]{2}{*}{ Don't agree } & \multicolumn{3}{|l|}{ 66. I don't accept my own limitations. } \\
\hline & & & & Agree & Don't agree \\
\hline \multirow{2}{*}{$\begin{array}{l}59 . \text { I fell free to be angry at } \\
\text { people I care for. }\end{array}$} & & & 67. I fell I cannot do many things. & & \\
\hline & Agree & Don't agree & & Agree & Don't agree \\
\hline \multirow{2}{*}{$\begin{array}{l}60 . \text { I can show my feelings even } \\
\text { when people might see me. }\end{array}$} & & & 68. I like myself. & & \\
\hline & Agree & Don't agree & & Agree & Don't agree \\
\hline \multirow{2}{*}{$\begin{array}{l}\text { 61. I can't like people even if I } \\
\text { don't agree with tem. }\end{array}$} & & & 69. I am not an important person. & & \\
\hline & Agree & Don't agree & & Agree & Don't agree \\
\hline \multirow[t]{2}{*}{$\begin{array}{l}62 . \text { I am afraid of doing things } \\
\text { wrong. }\end{array}$} & & & $\begin{array}{l}70 . \text { I know how to make up for my } \\
\text { limitations. }\end{array}$ & & \\
\hline & Agree & Don't agree & & Agree & Don't agree \\
\hline \multirow{2}{*}{$\begin{array}{l}\text { 63. It is better to be yourself } \\
\text { than to be popular. }\end{array}$} & & & 71. Other people like me. & & \\
\hline & Agree & Don't agree & & Agree & Don't agree \\
\hline \multirow{2}{*}{$\begin{array}{l}64 . \text { I am loved because I give } \\
\text { love. }\end{array}$} & & & 72. I am confident with my abilities. & & \\
\hline & Agree & Don't agree & & Agree & Don't agree \\
\hline \multirow[t]{2}{*}{ 65. I know what I do best. } & & & & & \\
\hline & Agree & Don't agree & & ototal: & \\
\hline
\end{tabular}

